Goldschmidt 2021 Abstract

https://doi.org/10.7185/gold2021.4276

\section{Edutain the people! - Science Slams as a tool for scientific education and entertainment}

MARIA-ELENA VORRATH ${ }^{1}$ AND PHILIPP SCHRÖGEL ${ }^{2}$

${ }^{1}$ University Brest, CNRS, IRS

${ }^{2}$ Karlsruhe Institute of Technology, Institute of Technology Futures

Presenting Author: MariaElena.Vorrath@univ-brest.fr

Spot on: here is your science. Science slams, in analogy to poetry slams and similar to the famelab format (Zarkadakis, 2010), are short and entertaining presentations in bars, music clubs or other cultural locations that are often presented by early career scientists. The format provides simple access to broad audiences from several cultural and education backgrounds and allows to teach science in a comprehensive and simplified way in a relaxed atmosphere (Niemann et al., 2020). A science slam is usually organized as a competition between several scientist trying to reach as many points (or applause) from the audience. Presenters are allowed to use a power point presentation during their 10 minutes on stage and any additional equipment to make their research visible, understandable and recognizable. Not only funny presentations but also slams with a catching story line, critical contents or artistic performance (poems, live music etc.) are highly appreciated by the audience. Since 2008, science slams have a growing cultural impact in Germany and successful science slammers took opportunities to publish popular science books, reach large audiences with science communication via social media and to build alternative careers besides academia. Here I present the science communication approach and edutainment elements such as metaphors and images from my presentation "Yesterday's snow - a climate crime story" about Antarctic sea ice reconstructions and paleoclimatology with organic biomarkers explained as a detective story. I like to encourage everyone to put on their lab coats, load your pipettes, hit the stage and edutain the people.

Niemann, P., Bittner, L., Schrögel, P. and Hauser, C.: Science Slams as Edutainment: A Reception Study, Media Commun., 8(1), 177-190, doi:10.17645/mac.v8i1.2459, 2020.

Zarkadakis, G.: FameLab: A Talent Competition for Young Scientists, Sci. Commun., 32(2), 281-287, doi:10.1177/1075547010368554, 2010.

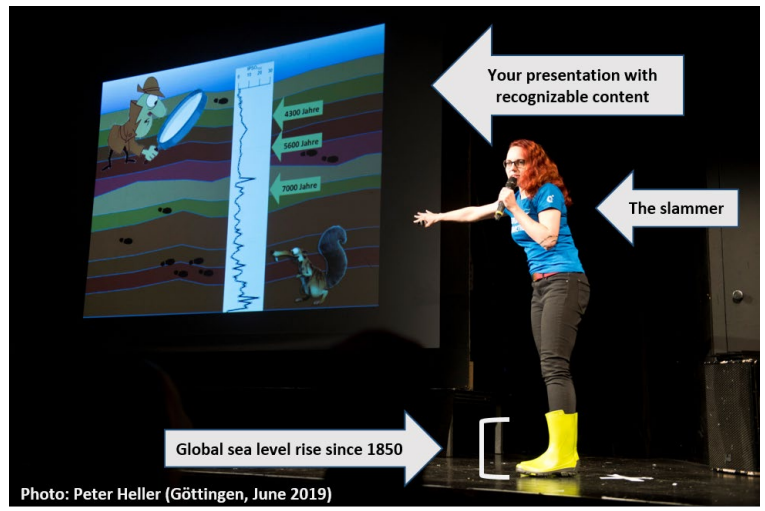

